\title{
The Draft Optional Protocol to the International Covenant on Economic, Social and Cultural Rights
}

\section{Lillan Chenwi and Christopher M bazira}

$\mathrm{H}$ istorically, economic, social and cultural rights (ESC rights) have received less protection through enforcement mechanisms than civil and political rights. Victims of ESC rights violations do not have the opportunity of submitting formal complaints to the Committee on Economic, Social and Cultural Rights (CESCR), the supervisory body of the International Covenant on Economic, Social and Cultural Rights (ICESCR). Conversely, the 1976 Optional Protocol to the International Covenant on Civil and Political Rights allows victims to lodge complaints with the Human Rights Committee (HRC), the supervisory body of the International Covenant on Civil and Political Rights (ICCPR).

An optional protocol to the ICESCR has long been advocated as a means of ensuring that, just like victims of civil and political rights violations, victims of ESC rights have access to remedies at the international level.

The journey towards the adoption of the Optional Protocol to the ICESCR (the Optional Protocoll) has been riddled with obstacles and setbacks revolving on the continuing doubts about the justiciability of ESC rights by some state parties to the ICESCR.

However, a flicker of light signalling hope for the adoption of a complaints mechanism is now visible. In 2006, governments will decide whether or not to draft an optional protocol permitting the consideration of complaints under the ICESCR. The decision reached will have immense repercussions for the realisation of ESC rights at international, regional and domestic levels.

The progress made thus far has resulted from the efforts of several role players, including agencies of the United Nations, some state parties to the ICESCR (though not all), intergovernmental organisations, academics, and non-governmental organisations (NGOs).

The NGOs' campaign for recognising the complaints procedure for ESC rights has been mobilised mainly through the NGO Coalition for an Optional Protocol (the NGO Coalition).

We focus here on some of the key proposals for an effective complaints mechanism advocated by the NGO Coalition. They are that the Optional Protocol should:

- include both communications and enquiry procedures;

- apply to all rights protected by the ICESCR and all levels of state obligations;

- enshrine wide rules of standing;

- make provision for a follow-up mechanism; and

- not make allowance for reservations.
Before we examine each of these components, it is worthwhile tracing the journey towards a complaints mechanism and highlighting the benefits of adopting the Optional Protocol. While the beginning of this journey predates the ICESCR's adoption, we intend to trace it from the time the CESCR reopened the issue.

\section{The historical background} In 1990 the CESCR started discussing the desirability and modalities of an individual complaint procedure for ESC rights by way of an optional protocol to the ICESCR. Subsequently, the 1993 Vienna Declaration and Program of Action (UN document A/Conf.157/ 23) urged the UN Commission on Human Rights (UNCHR) and the CESCR to continue work on it.

In 1996, the CESCR reached consensus on the need for an individual complaints procedure. It 
then finalised a draft Optional Protocol, which was presented to the UNCHR in 1997 (UN document E/ CN.4/1997/105) and later to states, intergovernmental organisations and $\mathrm{NGOs}$ for their comments. Most member states did not submit comments while $\mathrm{NGOs}$ strongly supported the draft Optional Protocol.

In 2001, the UNCHR appointed an independent expert to examine the draft Optional Protocol, the comments made on it by states, intergovernmental organisations and NGOs, as well as the report of a workshop held in 2001 on the justiciability of ESC rights and the draft Optional Protocol.

$\ln 2002$, the expert submitted his first report, which was in favour of the adoption

Australia and
the United
States are
opposed to the
drafting of an
optional
protocol.
of the draft Optional Protocol (E/CN.4/2002/57). In his second report, the Independent Expert recommended that the UNCHR should establish an OpenEnded Working Group (OEWG) with the mandate to consider options regarding the elaboration of an optional protocol to the ICESCR.

In 2003, the UNCHR agreed to convene the OEWG to consider the issue. The UNCHR, Special Rapporteurs consulted by the OEWG, representatives of the International Labour Organisation (ILO) and UN Educational, Scientific and Cultural Organisation (UNESCO) and almost all of the experts participating in the discussions, as well as NGOs, Latin American and African countries and some European countries, have supported the drafting of an optional protocol. it would:
However, the United States (US) and Australia are opposed to it. They continue to raise concerns about the justiciability of ESC rights. These states still contend that ESC rights are vague and demand a great deal of resources. They ignore the fact that civil and political rights also require significant resources and have only been clarified after repeated application and elaboration by courts. ESC rights should be afforded a similar opportunity to develop through a case-by-case interpretation by courts.

Other countries, such as Canada, Sweden and the United Kingdom, though no longer opposed to the move towards elaborating an optional protocol, do not support the idea that it should apply to all rights under the ICESCR for essentially the same reasons put forward by Australia and the US.

\section{The benefits of the Optional Protocol}

If an Optional Protocol is adopted, it would benefit not only individuals but state parties and the international community as well, in that

- bring the ICESCR into line with other human rights treaties by placing ESC rights on equal footing with civil and political rights, thereby emphasising their indivisibility, interrelatedness and interdependence;

- provide individuals and groups alleging violations of ESC rights with access to an international adjudicative procedure and remedies;
- lead to clarification of the nature of ESC rights and the obligations they engender; and

- encourage states to take steps towards the full implementation of ESC rights.

\section{Components of an effective optional protocol} As noted above, the NGO Coalition has proposed that an effective optional protocol should contain certain key elements. These proposals were included in a Joint NGO Submission to the OEWG, which met from 6-17 February 2006 in Geneva. The meeting was the last opportunity for governments to express their views on the Optional Protocol. These key components are discussed below.

\section{(a) Communications and enquiry procedures}

The NGO Coalition has been pushing for the idea that the Optional Protocol should contain both a communications and an enquiry procedure. The communications procedure would enable individuals to file complaints on specific violations of their ESC rights before the CESCR. The enquiry procedure would enable the CESCR to initiate, on the basis of reliable information, enquiries into grave or systematic violations of ESC rights.

\section{(b) Indivisibility of all rights}

The procedures established under the Optional Protocol should cover all the rights and obligations under the ICESCR. One of the most controversial issues has been whether it should apply to all of the rights recognised under the ICESCR or only to some. Some states parties have proposed that the Protocol 
should allow states parties, on ratification, to choose the rights that would apply to them (commonly known as the 'à la carte approach'). This has not been used before within the UN human rights treaty-based system.

The CESCR has warned that the à la carte approach to the enforcement of ESC rights would allow states to obtain the prestige associated with ratification of the Optional Protocol while at the same time incurring minimum obligations.

The NGO Coalition has pointed out that the a la carte approach would undermine the integrity and independence of the rights in the ICESCR. This is because it would allow states to 'opt out' of the obligation to provide effective remedies to particular rights or components of rights in the Covenant. This would reinforce the idea that some rights are different in nature and require a lesser level of protection than others do.

As argued above, this approach is unprecedented in the UN human rights treaty-based system. It would blatantly contradict the principle enunciated clearly by the CESCR that 'effective remedies' should be made available to all rights recognised in the ICESCR, even if such remedies may not always be judicial.

The NGO Coalition has also rejected as untenable the approach that allows states parties to subject themselves only to selected levels of obligations. Instead, it has argued that the complaints and enquiry procedures should provide the possibility of reviewing all aspects of ESC rights and all levels of state obligations - to respect, protect, or fulfil these rights.

In the NGO Coalition's view, a selective enforcement of state obligations would ignore the importance of maintaining a unitary and indivisible framework of human rights obligations.

\section{(c) Self determination}

There has been considerable controversy about whether the right to selfdetermination (article 12 of ICESCR) should be subjected to the complaints mechanism.

It has been argued that the inclusion of this right poses the danger that the procedure might be abused for political reasons.

The NGO Coalition maintains that the right to self-determination should indeed be subjected to the complaints mechanism.

This right is also included in the ICCPR and is already formally subject to individual complaints under the Optional Protocol to the ICCPR.

The position of the CESCR has always been that, in addition to its civil and political dimensions, this right has economic, social and cultural dimensions that merit protection under the optional protocol. To justify inclusion of this right, the NGO Coalition has given the example of indigenous peoples. The exclusion of this right would deny them their rights to cultural, economic and social self-determination.

\section{(d) The role of NGOs}

The NGO Coalition has also recommended that the Optional Protocol should make provision for the participation of $\mathrm{NGO}_{\mathrm{s}}$ in its procedures by allowing representative or group complaints.

Such a provision would help to protect victims of human rights who are at risk of abuse or ill-treatment for directly engaging in the process and ensure that vulnerable, poor or marginalised individuals or groups have access to these procedures.

While the Utrecht Draft of the Optional Protocol ISIM Special No. 18) restricted standing to individuals, groups or organisations claiming to be victims, the CESCR has always recommended that standing should be understood in wide terms.

The NGO Coalition fully supports the CESCR's view.

\section{(e) Reservations}

The NGO Coalition proposes that reservations to any provision of the Optional Protocol should not be allowed since the treaty is by its very nature optional. Through reservations, rights that are interdependent and overlapping could be severed. Thus, reservations would undermine the indivisibility, interdependence and interrelatedness of the rights contained in the ICESCR.

\section{(f) Follow-up mechanism}

The NGO Coalition has proposed that the Optional Protocol should make provision for a follow-up mechanism to ensure that the decisions and recommendations made are implemented and enforced. According to the CESCR, a follow-up mechanism could take different forms, including calling on the offending state to discuss the 
measures it has taken to give effect to the recommendations with the CESCR, inviting the state party to include in its report the details of the measures taken and including in its annual report the response of the State to its recommendations.

The NGO Coalition argues that this procedure would open an avenue for addressing problems encountered when implementing orders and would provide guidance and support to the states regarding the measures taken to comply with the order.

\section{(g) Admissibility}

Lastly, the NGO Coalition has argued that the Optional Protocol should not limit the territorial and jurisdictional application of the ICESCR or the temporal jurisdiction of the CESCR, as is the case with most other complaints mechanisms. Further, it has submitted that the 'exhaustion of domestic remedies' rule should not apply in cases where the remedies available are likely to be un-reasonably prolonged or ineffective.

Some states have also proposed the inclusion of the requirement that regional remedies should be exhausted first before a complaint can be lodged with the CESCR. It has been argued that this requirement would protect regional human rights systems from being pre-empted by the UN systems. While the NGO Coalition recognises the importance of regional mechanisms, it maintains that these should play a complementary role to UN mechanisms rather than provide a basis for denying complaints from regions where regional remedies are available.

\section{Conclusion}

The impact of that the Optional Protocol will have on the realisation of ESC rights will depend largely on its substance. As has been shown in this article, the NGO Coalition has argued emphatically that the Optional Protocol should affirm, without restrictions or reservations, that ESC rights, like civil and political rights, can only be properly understood and elaborated if claimants of these rights are fully heard. Restrictions on the justiciability of any rights or enforceability of any obligations under the ICESCR would reinforce the second-class treatment of ESC rights in the UN system and have a negative impact on domestic advocacy for the better protection of these rights.

\section{Lilian Chenwi and Christopher}

$\mathbf{M}$ bazira are both researchers in the Socio-Economic Rights Project, Community Law Centre, and UWC.

The authors would like to thank Bruce Porter, Director of the Special Rights Advocacy Centre, Canada, and Nathalie Mivelaz, International Secretariat Manager/UN Coordinator for the Centre on Housing Rights and Evictions, who provided useful information and comments on this paper. They are both members of the Steering Committee of the NGO Coalition.

Further information on the Optional Protocol to the ICESCR and the work of the NGO Coalition is available at the following website: www.escrprotocolnow.org 